\title{
Aspirin inhibits tumor progression and enhances cisplatin sensitivity in epithelial ovarian cancer
}

\author{
Jianfeng Guo ${ }^{\text {Equal first author, } 1}$, Yapei Zhu ${ }^{\text {Equal first author, } 1}{ }^{,}$, Lili Yu ${ }^{1}$, Yuan Li ${ }^{1}$, Jing Guo ${ }^{1}$, Jing Cai ${ }^{1}$, Lin Liu ${ }^{\text {Corresp., } 1}{ }^{1}$, Zehua \\ Wang ${ }^{\text {Corresp. } 1}$ \\ ${ }^{1}$ Department of Obstetrics and Gynecology, Union Hospital, Tongji Medical College, Huazhong University of Science and Technology, Wuhan, China \\ Corresponding Authors: Lin Liu, Zehua Wang \\ Email address: liulinjj@hotmail.com, zehuawang@hust.edu.cn
}

Background. Ovarian cancer is the most common gynecological malignancy and is difficult to manage due to the emergence of resistance to various chemotherapeutic drugs. New efforts are urgently awaited. Aspirin, traditionally considered a nonsteroidal antiinflammatory drug (NSAID), has been reported to show potential chemopreventive effects. Therefore, we aimed to investigate the anticancer effect and explore the underlying molecular mechanisms of aspirin in epithelial ovarian cancer (EOC) cells.Methods. We conducted wound healing, transwell migration, EdU cell proliferation, colony formation and apoptosis detection assays to observe the effects of aspirin on the migration, proliferation and apoptosis of EOC cells (A2870, Caov-3, SK-OV-3). EOC cells were treated with a combination of aspirin and cisplatin (CDDP) to observe the enhancing effect of aspirin on CDDP sensitivity. Orthotopic xenograft models of ovarian cancer established with A2780Luciferase-GFP cells were applied to compare the tumor growth inhibition abilities in the control, CDDP and CDDP plus aspirin groups through in vivo imaging, which can be used to continuously monitor tumor growth. The expression and acetylation levels of p53 in EOC cells treated with aspirin were determined by western blotting, and p53 acetylation levels were examined in tumors harvested from the transplanted mice. Quantitative real-time PCR was used to assess the mRNA expression of p53 target genes.Results. Aspirin inhibited migration and proliferation and induced apoptosis in EOC cell lines in a concentration-dependent manner. In vitro, aspirin enhanced the sensitivity of EOC cells to CDDP by enhancing its inhibitory effect on proliferation and its inductive effect on apoptosis. In vivo, the differences in the tumor growth inhibition rates among thedifferent CDDP experimental groups were statistically significant $(p<0.05)$. Aspirin did not affect p53 protein expression but increased the p53 acetylation level in a concentrationdependent manner. In addition, the mRNA levels of p21, bax, foxf1, puma, and rad in EOC cells were significantly increased by aspirin treatment.Conclusion. Aspirin can inhibit tumor progression and enhance the CDDP sensitivity of EOC cells. These antitumor effects 
of aspirin might be mediated by p53 acetylation and subsequent activation of p53 target genes. 


\section{Aspirin inhibits tumor progression and enhances 2 cisplatin sensitivity in epithelial ovarian cancer}

3 Jianfeng Guo , Yapei Zhu\#, Lili Yu, Yuan Li, Jing Guo, Jing Cai, Lin Liu*, and Zehua Wang*

4 Department of Obstetrics and Gynecology, Union Hospital, Tongji Medical College, Huazhong

5 University of Science and Technology, Wuhan, China.

6

7 \#Contributed equally to this work.

9 *Corresponding Authors:

10 Zehua Wang

11 \#1277 Jiefang Avenue, Wuhan 430022, China.

12 Email address: zehuawang@163.net

13 Lin Liu

14 \#1277 Jiefang Avenue, Wuhan 430022, China.

15 Email address: liulinjj@hotmail.com

16 


\section{Abstract}

18 Background. Ovarian cancer is the most common gynecological malignancy and is difficult to manage due to the emergence of resistance to various chemotherapeutic drugs. New efforts are urgently awaited. Aspirin, which is traditionally considered a nonsteroidal anti-inflammatory drug (NSAID), has been reported to exert potential chemopreventive effects. Therefore, we aimed to investigate the anticancer effect and explore the underlying molecular mechanisms of aspirin on epithelial ovarian cancer (EOC) cells.

24 Methods. We conducted wound healing, transwell migration, EdU cell proliferation, colony 25 formation and apoptosis detection assays to observe the effects of aspirin on the migration, proliferation and apoptosis of EOC cells (A2870, Caov-3, and SK-OV-3). EOC cells were treated with a combination of aspirin and cisplatin (CDDP) to observe the effect of aspirin on enhancing CDDP sensitivity. Orthotopic xenograft models of ovarian cancer established with A2780-Luciferase-GFP cells were applied to compare tumor growth inhibition in the control, CDDP and CDDP plus aspirin groups through in vivo imaging, which can be used to continuously monitor tumor growth. The expression and acetylation levels of p53 in EOC cells treated with aspirin were determined using western blotting, and p53 acetylation levels were examined in tumors harvested from the transplanted mice. Quantitative real-time PCR was used to assess the mRNA expression of p53 target genes.

Results. Aspirin inhibited migration and proliferation and induced apoptosis in EOC cell lines in a concentration-dependent manner. In vitro, aspirin enhanced the sensitivity of EOC cells to CDDP by increasing its inhibitory effect on proliferation and its effect on inducing apoptosis. In vivo, the differences in the tumor growth inhibition rates among the different CDDP experimental groups were statistically significant $(\mathrm{p}<0.05)$. Aspirin did not affect $\mathrm{p} 53$ protein expression but increased the $\mathrm{p} 53$ acetylation level in a concentration-dependent manner. In addition, the mRNA levels of CDKN1A, BAX,FOXF1, PUMA, and RRAD in EOC cells were

42 significantly increased by the aspirin treatment.

43 Conclusions. Aspirin inhibits tumor progression and enhances the CDDP sensitivity of EOC

44 cells. These antitumor effects of aspirin might be mediated by p53 acetylation and subsequent 45 activation of p53 target genes.

\section{Keywords}

aspirin, ovarian cancer, cisplatin, p53, acetylation 
49

50

51

52

53

54

55

56

57

58

59

60

61

62

63

64

65

66

67

68

69

70

71

72

73

74

75

76

77

78

79

80

81

82

83

84

85

86

87

88

\section{Introduction}

Ovarian cancer is the most common gynecological malignancy, and in $75 \%$ of patients, malignant ovarian tumors are diagnosed at an advanced stage due to the absence of symptoms in early stages (Siegel \& Miller \& Jemal, 2015). Platinum-based combination chemotherapy has been a standard first-line treatment for advanced ovarian cancer, but the development of chemotherapeutic resistance in cancer cells is a major clinical barrier to the successful treatment of cancer (Szakacs et al., 2006). TP53 mutation is a main mechanism inhibiting propagation of the DNA damage signal to the apoptotic machinery, thus leading to the development of drug resistance (Eckstein, 2011).

Aspirin (acetylsalicylic acid) is a nonsteroidal anti-inflammatory drug (NSAID); NSAIDs are widely prescribed analgesic and anti-inflammatory agents. Recently, emerging evidence showing the benefits of aspirin in cancer prevention has ignited renewed interest in aspirin research. Data from numerous studies have shown that prolonged intake of aspirin reduces the risk of and improves survival in patients with several cancers, including colon, breast, lung, prostate, and endometrial cancers (Bardia et al., 2011; Lim et al., 2012; Huang et al., 2014; Cao et al., 2016; Chen, 2017; Takiuchi et al., 2018; Gan et al., 2019; Loomans-Kropp et al 2019). Regular aspirin use is related to a reduction in the ovarian cancer risk (Trabert et al., 2014; Trabert et al., 2019; Hurwitz et al., 2020). Furthermore, Merritt et al. recently assessed the relations between aspirin, other NSAIDs, paracetamol, and ovarian cancer-specific survival after an ovarian cancer diagnosis in approximately 1000 cases. Their results suggested that women who used aspirin or NSAIDs after diagnosis experienced a prolonged ovarian cancer-specific survival compared with never-users (Merritt et al., 2018). Another small cohort study of women with clear cell ovarian cancer $(n=77)$ reported that aspirin use correlated with longer disease-free and overall survival, and it retained independent significance as a positive prognostic factor (Wield et al., 2018).

The mechanism underlying the efficacy of aspirin involves the inhibition of cyclooxygenase (COX) enzymes through irreversible acetylation of serine residues (Eckstein, 2011; Cuzick et al., 2009; Robles \& Harris, 2010; Silwal-Pandit \& Langerød \& Børresen-Dale, 2017), leading to inhibited synthesis of prostaglandins (PGs), which cause inflammation, swelling, pain and fever (Alfonso et al., 2014; Lucotti et al., 2019). Moreover, aspirin influences multiple COXindependent biological pathways in tumor progression and metastasis. Aspirin was found to inhibit various signaling pathways, such as the Ras/c-Raf, extracellular signal-regulated kinase (ERK)/MAPK, NF- $\kappa \mathrm{B}$, and mTOR pathways, in different cancer cells (Guo et al., 2016; Wu et al., 2020). Additionally, the chemopreventive mechanism of aspirin might involve the increased number of tumor-infiltrating lymphocytes in the tumor microenvironment. Hence, combination therapy with aspirin might overcome immune resistance and enhance the therapeutic efficacy of chemotherapeutics toward metastatic breast cancer (Liu et al., 2019).

Although the molecular mechanisms underlying the anticancer effects of aspirin have been extensively investigated, the involvement of numerous cellular components in ovarian cancer is still incompletely understood. Because of the mutation of TP53 in platinum-resistant epithelial 
89 ovarian cancer (EOC) and the acetylation effect of aspirin, we hypothesized that aspirin exerts an

90

91

92

93

94

95

96

97

98

99

100

101

102

103

104

105

106

107

108

109

110

111

112

113

114

115

116

117

118

119

120

121

122

123

124

125

126

127

anticancer effect on EOC through the acetylation of p53. Therefore, in this study, we

investigated whether aspirin increases the efficacy of cisplatin (CDDP) in EOC and initially

explored its underlying mechanism.

\section{Materials \& methods}

\section{Cell culture.}

The EOC cell lines A2780, Caov-3 and SK-OV-3 were purchased from the China Center for Type Culture Collection (CCTCC). A2780 and Caov-3 are ovarian adenocarcinoma cell lines derived from malignant tumor tissues of untreated patients with ovarian cancer. SK-OV-3 is an ovarian adenocarcinoma cell line derived from malignant ascites. All cell lines were maintained at $37^{\circ} \mathrm{C}$ in DMEM/F 12 (Thermo Fisher, Waltham, MA, USA) supplemented with $10 \%$ fetal bovine serum (FBS; Gibco, Carlsbad, CA, USA) in a 5\% $\mathrm{CO}_{2}$ atmosphere. Aspirin (Sigma, St. Louis, MO, USA) was added for the indicated times after 12-24 h of cell growth. All assays below were performed in triplicate.

\section{Cell viability assays.}

Cells were seeded at a density of 5000 cells/well in 96 -well tissue culture plates. Different concentrations of aspirin $(0.2 \mathrm{mM}, 0.4 \mathrm{mM}, 0.8 \mathrm{mM}, 1.6 \mathrm{mM}, 3.2 \mathrm{mM}$, or $6.4 \mathrm{mM})$ were added to the culture media after cell attachment, and five replicate wells for each concentration were established. Forty-eight hours after treatment, $20 \mu \mathrm{l}$ of $5 \mathrm{mg} / \mathrm{ml} \mathrm{3-(4,5-dimethylthiazol-2-yl)-2,5-}$ diphenyltetrazolium bromide (MTT) were added to the media, and the cells were further incubated for $4 \mathrm{~h}$. Subsequently, the cells were solubilized in $100 \mu \mathrm{l}$ of solubilization solution for $8 \mathrm{~h}$. The optical density (OD) at $570 \mathrm{~nm}$ was measured using a microplate reader (Bio-Rad, Berkeley, CA, USA).

\section{Cell proliferation assays.}

Cells were seeded in a 96-well tissue culture plate (Corning Costar, Corning, NY, USA) and adjusted to a density of $5000 \mathrm{cells} / \mathrm{well}$. After treatment with different concentrations of aspirin $(0 \mu \mathrm{M}, 100 \mu \mathrm{M}$, and $1000 \mu \mathrm{M})$ and/or CDDP $(20 \mu \mathrm{M})$, cells were fixed and stained with an EdU cell proliferation kit (RiboBio Co., Guangzhou, China). Cells were immediately observed under a fluorescence microscope (Olympus, Tokyo, Japan), and cells in three random fields per well were counted $(100 \times)$.

\section{Colony formation assays.}

Cells were seeded in 6-well tissue culture plates in triplicate, and the density was adjusted to 500 cells/well. Cells were cultured in DMEM/F12 supplemented with 10\% FBS and different concentrations of aspirin $(0 \mu \mathrm{M}, 25 \mu \mathrm{M}, 100 \mu \mathrm{M}, 500 \mu \mathrm{M}, 1000 \mu \mathrm{M}$, and $25 \mu \mathrm{M})$ and/or CDDP $(5 \mu \mathrm{M})$ at $37^{\circ} \mathrm{C}$ in a $5 \% \mathrm{CO}_{2}$ incubator (Heraeus, Hanau, Germany) for 14 days. Next, cells in the wells were fixed with methanol and stained with $0.1 \%$ crystal violet; the cell colonies formed were then visible to the naked eye.

Flow cytometry analysis.

Peer) reviewing PDF | (2020:09:53184:2:0:NEW 16 May 2021) 
128 Cells were plated in triplicate in a six-well plate at a density of $1 \times 10^{5}$ cells/well and

129

130

131

132

133

134

135

136

137

138

139

140

141

142

143

144

145

146

147

148

149

150

151

152

153

154

155

156

157

158

159

160

161

162

163

164

165

166

167

incubated for $24 \mathrm{~h}$. Then, cells were treated with different concentrations of aspirin $(0 \mu \mathrm{M}, 100$ $\mu \mathrm{M}$, and $1000 \mu \mathrm{M})$ and/or CDDP $(20 \mu \mathrm{M})$. After a 48 -h incubation at $37^{\circ} \mathrm{C}$, cells were harvested, trypsinized and washed with cold phosphate-buffered saline (PBS). Subsequently, cells were stained with APC Annexin V and propidium iodide (PI) (BioLegend, Inc., San Diego, CA, USA). The stained cells were immediately analyzed using an LSR flow cytometer (Beckman Coulter, Inc., 250 S. Kraemer Boulevard, Brea, CA, USA), and the data were analyzed using Summit 6.2 software (Beckman Coulter, Inc., 250 S. Kraemer Boulevard, Brea, CA, USA).

\section{Western blot analysis.}

After treatment with different concentrations of aspirin $(0 \mu \mathrm{M}, 100 \mu \mathrm{M}$, and $1000 \mu \mathrm{M})$ for $24 \mathrm{~h}$, cells were collected in cold Nonidet P40 (NP40) buffer containing a protease inhibitor cocktail for $30 \mathrm{~min}$ and centrifuged at $13000 \times \mathrm{g}$ for $10 \mathrm{~min}$; subsequently, the supernatants were collected. The protein concentration was measured with a bicinchoninic acid (BCA) assay. Proteins in the samples were separated by $8 \%$ sodium dodecyl sulfate-polyacrylamide gel electrophoresis (SDS-PAGE) and transferred onto polyvinylidene difluoride (PVDF) membranes. Membranes were blocked with 5\% nonfat milk in Tris-buffered saline containing Tween 20 (TBST) for $1 \mathrm{~h}$ at room temperature and incubated with rabbit anti-p53 (1:1500; Cell Signaling Technology, Boston, MA, USA), rabbit anti-acetylated p53 (K382) (1:500; Abcam, Cambridge, UK), and mouse anti- $\beta$-actin (1:4000; Cell Signaling Technology, Boston, MA, USA) antibodies at $4^{\circ} \mathrm{C}$ overnight. Horseradish peroxidase-conjugated anti-rabbit or anti-mouse secondary antibodies (1:5000; Cell Signaling Technology, Boston, MA, USA) were used for detection as appropriate. Immunoreactions were visualized with an enhanced chemiluminescence kit (Bio-Rad, Berkeley, CA, USA), and the gray values of the bands were quantified with Quantity One Software (Bio-Rad, Berkeley, CA, USA) or a Molecular Imager ChemiDoc ${ }^{\mathrm{TM}}$ $\mathrm{XRS}_{+}$system with Image Lab ${ }^{\mathrm{TM}}$ software (Bio-Rad, Berkeley, CA, USA).

\section{Quantitative real-time polymerase chain reaction (qPCR).}

After treatment with different concentrations of aspirin $(0 \mu \mathrm{M}, 100 \mu \mathrm{M}$, and $1000 \mu \mathrm{M})$ for $24 \mathrm{~h}$, total cellular RNA was extracted from cultured cells with TRIzol reagent (Thermo Fisher, Waltham, MA, USA) according to the manufacturer's protocol. The quality and quantity of total RNA were evaluated with a NanoDrop 2000/2000C spectrophotometer (Thermo Fisher, Waltham, MA, USA), and cDNAs were subsequently synthesized using a reverse transcription kit (Takara, Tokyo, Japan) and the following primers: CDKN1A, upstream 5'CGATGGAACTTCGACTTTGTCA-3' and downstream 5'GCACAAGGGTACAAGACAGTG-3'; $B A X$, upstream 5'-CCCGAGAGGTCTTTTTCCGAG3' and downstream 5'-CCCGAGAGGTCTTTTTCCGAG-3'; FOXF1, upstream 5'GCGGCTTCCGAAGGAAAT-3' and downstream 5'-CAAGTGGCCGTTCATCATGC-3'; PUMA, upstream 5'-CAAGTGGCCGTTCATCATGC-3' and downstream 5'CAAGTGGCCGTTCATCATGC-3'; RRAD, upstream 5'-CAAGTGGCCGTTCATCATGC-3' and downstream 5'-CAAGTGGCCGTTCATCATGC-3'; and $\beta$-actin, upstream 5'GCCAACACAGTGCTGTCTGG-3' and downstream 5'-

Peer] reviewing PDF | (2020:09:53184:2:0:NEW 16 May 2021) 
168 GCTCAGGAGGAGCAATGATCTTG-3'. $\beta$-Actin expression was used for normalization. PCR

169

170

171

172

173

174

175

176

177

178

179

180

181

182

183

184

185

186

187

188

189

190

191

192

193

194

195

196

197

198

199

200

201

202

203

204

205

206

207

was performed in an Applied Biosystems StepOnePlus Real-time PCR system (Thermo Fisher, Waltham, MA, USA) using SYBR Green Real-time PCR Master Mix (Takara, Tokyo, Japan). The reactions were performed with a two-step thermal cycling method, $95^{\circ} \mathrm{C}$ for 30 seconds and 40 PCR cycles of $95^{\circ} \mathrm{C}$ for 5 seconds and $66^{\circ} \mathrm{C}$ for 30 seconds, followed by a melting curve analysis. The relative expression levels were calculated using the $\mathrm{Ct}\left(2^{-\Delta \Delta \mathrm{Ct}}\right)$ method.

\section{Orthotopic xenograft mouse model of human EOC.}

The Institutional Animal Care and Use Committee of Tongji Medical College approved this research ([2014] IACUC Number: 399). Six-week-old female BALB/c-nu/nu mice were purchased from Beijing HFK Bioscience Co. and were housed in sterile cages with ad libitum access to food in a specific pathogen-free (SPF) barrier animal room at Tongji Medical College Experimental Animal Center. A2780-Luciferase cells were obtained by transfecting the EOC cell line A2780 with a lentivirus carrying the luciferase gene. A2780-Luciferase cells were suspended in serum-free medium, and the density was adjusted to $1 \times 10^{7}$ cells $/ \mathrm{ml}$. A $200-\mu 1$ aliquot of the cell suspension was subcutaneously injected into the right axilla of nude mice. When the tumor volume reached approximately $1 \mathrm{~cm}^{3}$, mice were anesthetized with isoflurane, and the tumor was harvested. Subsequently, the tumor was cut into fragments with a volume of approximately 1-2 $\mathrm{mm}^{3}$. Eighteen mice were randomly divided into three groups according to a random number table $(n=6)$. Then, six mice per group were inoculated with one tumor fragment in the left ovary. Mice in the CDDP group were treated with CDDP by intraperitoneal injection and with water by gavage, mice in the CDDP plus aspirin group were treated with CDDP by intraperitoneal injection and aspirin by gavage, and mice in the control group were treated with saline by intraperitoneal injection and water by gavage. Only the administering experimenter was aware of the group allocation. The tumor fragments were transplanted on day 0 , and after an intraperitoneal injection of XenoLight D-Luciferin Potassium Salt (Perkin Elmer, Waltham, MA, USA), tumor growth was observed with an IVIS Lumina II (Caliper Life Science, Waltham, MA, USA) beginning on day 8 and then once per week thereafter to obtain in vivo bioluminescence images. The acquired optical data were analyzed using Living Image software. Aspirin was initially administered on day 9 at a dose of $20 \mathrm{mg} / \mathrm{kg}$ and then every other day thereafter, while CDDP administration was initiated at a dose of $3 \mathrm{mg} / \mathrm{kg}$ on day 17 and then every fourth day thereafter. All mice were euthanized via overdose isoflurane inhalation on day 36 and necropsied for the measurement of tumor diameters with Vernier calipers. The tumor volume and relative tumor inhibition rate were calculated using the following formulas: $\mathrm{V}=\left(\mathrm{L} \times \mathrm{W}^{2}\right) / 2$ and $\mathrm{R}=(\mathrm{V}$ control group $\left.-\mathrm{V}_{\text {treatment group}}\right) / \mathrm{V}$ control group.

\section{Immunohistochemistry (IHC).}

Tissue sections (4- $\mu \mathrm{m}$ thick) were prepared from formalin-fixed, paraffin-embedded blocks and were immunohistochemically stained with rabbit anti-p53 (1:100; Abcam, Cambridge, UK), rabbit anti-acetylated p53 (K382) (1:100; Abcam, Cambridge, UK), rabbit anti-Ki67 (1:100; Abcam, Cambridge, UK), rabbit anti-caspase 3 (1:100; Cell Signaling Technology), and rabbit anti-cleaved caspase 3 (1:100; Cell Signaling Technology) antibodies. Localization of the target

Peer] reviewing PDF | (2020:09:53184:2:0:NEW 16 May 2021) 
208 protein was visualized by incubating sections with a freshly prepared 3,3'-diaminobenzidine

209 (DAB) solution for $3 \mathrm{~min}$. PBS was substituted for the primary antibody as the negative control.

210 Three slides from each tissue were independently evaluated by two observers with an Olympus

211 FV500 optical microscope (Olympus, Tokyo, Japan).

212 Quantitative analysis of images of immunohistochemical staining.

213 The expression of target proteins in tumors harvested from transplanted mice was quantified

214 by determining the relative percentage of the positive-stained area to the selected total tissue area

215 and the average staining intensity normalized to the intensity of the selected stroma with an

216 imaging processor to exclude the influence of the tumor volume. Slides were reviewed under a

217 light microscope at $400 \times$ magnification, and five regions were randomly selected per slide.

218 Image J software was used to analyze the percentage of the positive-stained area and the staining

219 intensity in the tumor tissue from every region, and the overall average value across the slides

220 was considered the level of protein expression.

221 Statistical analysis.

222 All statistical analyses were performed using SPSS software version 22.0. Data are

223 presented as the means \pm standard deviations ( $S D, n \geq 3$ ) values. Student's t-test or one-way

224 ANOVA was adopted to compare group differences, and significance was defined as $\mathrm{p}<0.05$.

225

226

227

228

229

230

231

232

233

234

235

236

237

\section{Results}

\section{Aspirin inhibits the growth of human EOC cells in vitro.}

A survival curve based on the results of MTT assays showed that the half-maximal inhibitory concentration (IC50) values of aspirin in the EOC cell lines A2780, Caov-3 and SKOV-3 were $1.27(95 \% \mathrm{CI}, 0.93-1.72) \mathrm{mM}, 2.05(95 \% \mathrm{CI}, 1.83-2.30) \mathrm{mM}$, and 1.54 (95\% CI, 1.30-21.82) $\mathrm{mM}$, respectively (Fig. 1A). Thus, we conducted the functional trial in vitro with doses of 100 and $1000 \mu \mathrm{M}$, which were lower than the IC50 in each cell line.

The results of EdU cell proliferation and colony formation assays illustrated that the proliferation and growth of the A2780, Caov-3 and SK-OV-3 cell lines were significantly suppressed by aspirin in a concentration-dependent manner (Figs. 1B-E and S1A-D). Moreover, as the aspirin concentration increased, the apoptosis rate in the EOC cell lines increased significantly, and the apoptosis rate differed significantly among the different concentrations

238 (Fig. 1F-G). In addition, the results of wound healing and transwell migration assays showed that 239 the migration of A2780, Caov-3 and SK-OV-3 cells was suppressed by aspirin in a 240 concentration-dependent manner (Fig. S2A-D).

241

242

243

244

245

246

247

\section{Aspirin enhances the CDDP sensitivity of EOC cells.}

A2780 and SK-OV-3 cells were treated with CDDP alone or in combination with aspirin to investigate the role of aspirin in mediating CDDP sensitivity in vitro. Cell proliferation (Figs. 2A-B and S3A) and colony formation (Figs. 2C-D and S3B) were significantly inhibited and cell apoptosis (Figs. 2E-F and S3C) was induced by CDDP alone in A2780 and SK-OV-3 cells compared to the corresponding control cells. Moreover, CDDP plus aspirin exerted a significantly stronger effect than CDDP alone.

Peer) reviewing PDF | (2020:09:53184:2:0:NEW 16 May 2021) 
248

249

250

251

252

253

254

255

256

257

258

259

260

261

262

263

264

265

266

267

268

269

270

271

272

273

274

275

276

277

278

279

280

281

282

283

284

285

286

287

Orthotopic xenograft mouse models of EOC were established with A2780-Luciferase cells, and tumor bioluminescence signals were visualized in situ to investigate the role of aspirin in mediating CDDP sensitivity in vivo (Fig. 3A). As shown in Fig. 3B, the tumor growth curve of the CDDP plus aspirin group was shallower than that of the CDDP alone group, and the CDDP alone group had a shallower curve than the control group. Moreover, the difference in the tumor volume among the three groups was consistent with the tumor growth curves (Fig. 3C-D). The tumor inhibition rates in the CDDP group and the CDDP plus aspirin group were $49.3 \%$ and $78.4 \%$, respectively.

In addition, the level of caspase 3 in the tumor tissue was not different among the three groups (control, CDDP, and CDDP plus aspirin); however, the level of cleaved caspase 3 was higher in the CDDP group than in the control group and was higher in the CDDP plus aspirin group than in the CDDP group (Fig. 3E). Ki67 expression was reduced in the CDDP group compared to the control group and was lower in the CDDP plus aspirin group than in the CDDP group (Fig. 3E).

\section{Aspirin acetylates p53 in EOC cells and subsequently activates p53-mediated} downregulation of target genes.

The expression of p53 was not different among the three groups (control, CDDP, and CDDP plus aspirin), but the acetylation level of p53 in the CDDP plus aspirin group was higher than that in both the control group and the CDDP group (Fig. 4A-B). As shown in Fig. 4C, the level of the p53 protein in the A2780 cell line remained unchanged after treatment with different concentrations of aspirin. However, as the aspirin concentration increased, the acetylation level of p53 gradually increased. Moreover, the mRNA expression levels of the p53 target genes CDKN1A, BAX, FOXF1, PUMA, and RRAD increased significantly in a concentrationdependent manner, as illustrated in Fig. 4D.

\section{Discussion}

The anticancer action of aspirin has recently received increasing attention. An inverse association between the intake of aspirin and the risk of many types of cancer, including ovarian cancer, has been identified in recent decades (Takiuchi et al., 2018; Gan et al., 2019; LoomansKropp et al 2019; Baandrup et al., 2015; Peres et al., 2016; Zhang et al., 2016). In addition to its use as an effective chemopreventive agent, aspirin can also prolong patient survival even after a cancer diagnosis, which suggests the potential for the adjunct use of aspirin in cancer chemotherapy (Merritt et al., 2018). However, despite these observations and reports, the mechanisms underlying the anticancer effects of aspirin are not well understood. In the present study, we demonstrated that both in vitro and in vivo, aspirin could inhibit tumor cell growth and mobility and enhance their sensitivity to CDDP, which is similar to the previous findings that the combination therapy with aspirin overcome immune resistance and enhance the therapeutic efficacy of chemotherapeutic agent toward metastatic breast cancer. (Liu et al., 2019).

Since plasma concentrations of intact aspirin can be up to $100 \mu \mathrm{M}$ after the administration of a single therapeutic dose (Roberts et al., 1983), this concentration was used to observe the 
288

289

290

291

292

293

294

295

296

297

298

299

300

301

302

303

304

305

306

307

308

309

310

311

312

313

314

315

316

317

318

319

320

321

322

323

324

325

326

327

cellular effects of aspirin in the present study. The results of wound healing, transwell migration, EdU cell proliferation and colony formation assays showed that aspirin inhibited the migration, proliferation and growth of A2780, Caov-3 and SK-OV-3 EOC cells, consistent with the results of previous studies (Huang et al., 2016).

Animal studies have indicated that aspirin significantly enhances the efficacy of CDDP in reducing the growth of orthotopic xenograft tumors formed by human EOC cells in mice. Notably, because of the gastrointestinal side effects of this drug, as well as the potential for gastroduodenal ulcers and bleeding, we treated mice with a safe dose of $20 \mathrm{mg} / \mathrm{kg}$, which was determined by an equivalent dose conversion from the dosage of $100 \mathrm{mg} /$ day used for oral lowdose aspirin therapy in humans. Moreover, in the present animal study, we established orthotopic xenograft models in mice (Kim et al., 2006) using a luciferase-labeled A2780 cell line and subsequently observed tumor growth using in vivo bioluminescence imaging after an intraperitoneal injection of D-luciferin potassium salt, which interacts with luciferase to generate an optical signal. Unlike previous studies using models established by an intraperitoneal injection of ovarian cancer cells or using subcutaneous tumor models (Huang et al., 2016), we surgically transplanted the tumor tissue into the ovaries of a mice; thus, our model more precisely mimicked the environment of human ovarian cancer. In addition, this approach enabled continual observation of tumor growth deep inside the abdominal cavity via in vivo imaging without the need to sacrifice the mice. Moreover, due to the principle of in vivo bioluminescence imaging, which detects the viable cells in the tumor, our approach provided a more accurate estimate of tumor activity than simply measuring the tumor volume. In summary, the results of our animal experiments were more convincing and reliable than those reported in other studies.

Regarding the potential mechanism, we elucidated that aspirin acetylates p53 at lysine 382 in EOC cells and subsequently activates p53 target genes, which regulate cell cycle arrest, migration and apoptosis.

Aspirin consists of two functional groups, an acetyl group and a salicylate group, both of which have their own distinct targets. The acetyl group of aspirin acetylates COX, thereby inducing its inhibition (Alfonso et al., 2014), and the salicylate group suppresses IкB kinase (IKK) $\beta$ and prevents NF- $\kappa \mathrm{B}$ activation (Kim et al., 2006); thus, both groups contribute to the anti-inflammatory properties of aspirin. Although most hypotheses have focused on the antiinflammatory activities of aspirin, this drug also interferes with ERK signaling, leading to ERK inhibition by preventing the binding of c-Raf to Ras in vitro (Guo et al., 2016). Moreover, aspirin reduces mTOR signaling by inhibiting the mTOR effectors S6K1 and 4EBP1 in colorectal cancer (Guo et al., 2016) and suppresses esophageal squamous cell carcinoma growth by inhibiting HBXIP and HMGA2 (Wu et al., 2020). In addition, aspirin induces concentrationdependent inhibition of the major oncogenic pathway, the $\mathrm{Wnt} / \beta$-catenin pathway, in colon cancer (Bos et al., 2006) and acetylates the tumor suppressor protein p53 at lysine 382 in MDAMB-231 breast cancer cells (Alfonso et al., 2009).

TP53 has been recognized as a tumor suppressor gene encoding the $\mathrm{p} 53$ protein in human cancers. The p53 protein is a transcription factor that controls the expression of genes and 
328

329

330

331

332

333

334

335

336

337

338

339

340

341

342

343

344

345

346

347

348

349

350

351

352

353

354

355

356

357

358

359

360

361

362

363

364

365

366

367

miRNAs affecting many important cellular processes. The chemotherapy drug CDDP activates the DNA damage response pathway, in which the tumor suppressor p53 controls cell cycle progression and apoptosis. However, studies have reported that the TP53 gene is mutated and inactivated in more than $50 \%$ of all tumors and that these mutations are associated with earlier onset of cancer and the development of drug resistance (Robles \& Harris, 2010). A considerably high mutation frequency of $50-100 \%$ is reported across all ovarian cancers (Silwal-Pandit \& Langerød \& Børresen-Dale, 2017). Meanwhile, p53 mutation can prevent the proper folding of the $\mathrm{p} 53$ protein or directly disrupt its DNA-binding ability, and thus the tumor may acquire new oncogenic properties such as drug-resistance (Raimundo et al., 2020). Posttranslational modifications (PTMs) of p53 are critical in modulating its tumor suppressor functions (Vousden \& Prives, 2009). Acetylation is an important PTM that increases p53 protein stability, its binding to low-affinity promoters and its interactions with other proteins (Reed \& Quelle, 2014). For instance, p53 acetylation at $\mathrm{K} 382$ promotes the recruitment of its co-activators to the CDKN1A promoter and increases histone acetylation following DNA damage (Reed \& Quelle, 2014); it also activates pro-apoptotic functions of BAX and PUMA (Yamaguchi et al., 2009). Moreover, RRAD and FOXF 1 are also upregulated by p53 activation, which may further inhibit cell migration (Hsiao et al., 2011; Tamura et al.,2013). In our study, aspirin acetylated p53 to subsequently increase the mRNA expression of its target gene CDKN1A in A2780 and SK-OV-3 EOC cells. Furthermore, aspirin activated other downstream target genes related to cell migration, such as RRAD and FOXF1, and genes related to apoptosis, i.e., PUMA and BAX. However, more studies are needed to confirm whether the anticancer efficacy of aspirin is mediated by this pathway.

According to previous research, A2780 and SK-OV-3 cells express the wild-type TP53 gene, while the TP53 gene is mutated in Caov-3 cells, which is a point mutation that resulted in a chain termination signal likely to truncate the p53 peptide at amino acid 135 (Skilling, 1996; Yaginuma \& Westphal,1992). The status of the TP53 gene in these three EOC cell lines was not validated in our study. Moreover, further research is required to investigate the potential differences in biological function between the acetylation of wild-type p53 versus mutant p53 in ovarian cancer. Beside p53 acetylation, as a multifunctional agent, Aspirin may exhibit anticancer effects through p53-independent pathways, such as inhibition of cyclin dependent kinases by aspirin metabolites and inhibition of nuclear- $\mathrm{kB}$ signaling through direct interactions with IאB kinase in colorectal cancers (Sankaranarayanan et al., 2020). The multi-targeting and dose-dependent action manner of aspirin makes its use in the treatment of cancer both promising and puzzling. Although we provide preliminary evidence regarding the potential benefit of adding aspirin to CDDP chemotherapy in ovarian cancer, the interactions between aspirin and traditional chemotherapeutic agents remains largely unclear.

In summary, aspirin inhibits tumor progression and enhances the CDDP sensitivity of EOC cells through p53 acetylation and subsequent activation of p53 target genes that regulate tumor migration, proliferation, and chemoresistance. These findings provide a theoretical basis for the use of aspirin in the treatment of ovarian cancer and lay the foundation for future research. 
368

369

370

371

372

373

374

375

376

377

378

379

380

381

382

383

384

385

386

387

388

389

390

391

392

393

394

395

396

397

398

399

400

401

402

403

404

405

\section{Acknowledgements}

This study was funded by the National Natural Science Foundation of China (No. $81672573)$.

\section{Disclosure Statement}

The authors have no relevant conflicts of interest to declare.

\section{References}

Alfonso L, Ai G, Spitale RC, Bhat GJ. 2014. Molecular targets of aspirin and cancer prevention. Br J Cancer 111: 61-67 DOI: 10.1038/bjc.2014.271

Alfonso LF, Srivenugopal KS, Arumugam TV, Abbruscato TJ, Weidanz JA, Bhat GJ. 2009. Aspirin inhibits camptothecin-induced p21cip1 levels and potentiates apoptosis in human breast cancer cells. Int J Oncol 34: 597-608 DOI: 10.3892/ijo_00000185

Bardia A, Olson JE, Vachon CM, Lazovich D, Vierkant RA, Wang AH, Limberg PJ, Anderson KE, Cerhan JR. 2011. Effect of aspirin and other nsaids on postmenopausal breast cancer incidence by hormone receptor status: Results from a prospective cohort study. Breast Cancer Res Treat 126: 149-155 DOI: 10.1007/s10549-010-1074-X

Baandrup L, Kjaer SK, Olsen JH, Dehlendorff C, Friis S. 2015. Low-dose aspirin use and the risk of ovarian cancer in Denmark. Ann Oncol 26: 787-792 DOI: 10.1211/cp.2018.20205738

Bos CL, Kodach LL, van den Brink GR, Diks SH, van Santen MM, Richel DJ, Peppelenbosch MP, Hardwich JCH. 2006. Effect of aspirin on the Wnt/ $\beta$-catenin pathway is mediated via protein phosphatase 2A. Oncogene 25: 6447-6456 DOI:

10.1038/sj.onc. 1209658

Cuzick J, Otto F, Baron JA, Brown PH, Burn J, Greenwald P, Jankowski J, La Vecchia C, Meyskens F, Senn HJ, Thun M. 2009. Aspirin and non-steroidal anti-inflammatory drugs for cancer prevention: An international consensus statement. Lancet Oncol 10: 501-507 DOI: 10.1016/s1470-2045(09)70035-X

Chen WY, Holmes MD. 2017. Role of Aspirin in Breast Cancer Survival. Curr Oncol Rep 19:48 DOI 10.1007/s11912-017-0605-6

Cao Y, Nishihara R, Wu K, Wang M, Ogino S, Willett WC, Spiegelman D, Fuchs CS, Giovannucci EL, Chan AT. 2016. Population-wide Impact of Long-term Use of Aspirin and the Risk for Cancer. JAMA Oncol e1-e8 DOI:10.1001/jamaoncol.2015.6396

Eckstein N. 2011. Platinum resistance in breast and ovarian cancer cell lines. J Exp Clin Cancer Res 30: 91 DOI: 10.1186/1756-9966-30-91

Guo H, Liu J, Ben Q, Qu Y, Li M, Wang Y, Chen W, Zhang J. 2016. The aspirin-induced long non-coding RNA OLA1P2 blocks phosphorylated STAT3 homodimer formation. Genome Biology. 17:24 DOI 10.1186/s13059-016-0892-5 
406

407

408

409

410

411

412

413

414

415

416

417

418

419

420

421

422

423

424

425

426

427

428

429

430

431

432

433

434

435

436

437

438

439

440

441

442

443

444

Gan H, Lin L, Hu N, Yang Y, Gao Y, Pei Y, Chen K, Sun B. 2019. Aspirin ameliorates lung cancer by targeting the miR-98/ WNT1 axis. Thoracic Cancer DOI:10.1111/17597714.12992

Hurwitz LM, Pinsky PF, Huang WY, Freedman ND, Trabert B. 2020. Aspirin use and ovarian cancer risk using extended follow-up of the PLCO Cancer Screening Trial. Gynecol Oncol 159(2):522-526 DOI: 10.1016/j.ygyno.2020.08.038

Huang TB, Yan Y, Guo ZF, Zhang XL, Liu H, Geng J, Yao XD, Zheng JH. 2014. Aspirin use and the risk of prostate cancer: A meta-analysis of 24 epidemiologic studies. Int Urol Nephrol 46: 1715-1728 DOI: 10.1007/s11255-014-0703-4

Huang Y, Lichtenberger LM, Taylor M, Bottsford-Miller JN, Haemmerie M, Wagner MJ, Lyons Y, Pradeep S, Hu W, Previs RA, Hansen JM, Fang D, Dorniak PL, Filant J, Dial EJ, Shen F, Hatakeyama H, Sood AK. 2016. Anti-tumor and anti-angiogenic effects of aspirin-pc in ovarian cancer. Mol Cancer Ther 15: 2894-2904 DOI: 10.1158/15357163.MCT-16-0074

Hsiao BY, Chen CC, Hsieh PC, Chang TK, Yeh YC, Wu YC, Hsu HS, Wang FF, Chou TY. 2011. $\mathrm{Rad}$ is a p53 direct transcriptional target that inhibits cell migration and is frequently silenced in lung carcinoma cells. J Mol Med 89(5):481-492 DOI: 10.1007/s00109-010-0717Z

Kim KS, Sengupta S, Berk M, Kwak YG, Escobar PF, Belinson J, Mok SC, Xu Y. 2006. Hypoxia enhances lysophosphatidic acid responsiveness in ovarian cancer cells and lysophosphatidic acid induces ovarian tumor metastasis in vivo. Cancer Res 66: 7983-7990 DOI: 10.1158/0008-5427.CAN-05-4381

Lim WY, Chuah KL, Eng P, Leong SS, Lim E, Lim TK, Ng A, Poh WT, Tee A, Teh M, Salim A, Seow A. 2012. Aspirin and non-aspirin non-steroidal anti-inflammatory drug use and risk of lung cancer. Lung Cancer 77: 246-251 DOI: 10.1016/j.lungcan.2012.03.005

Loomans-Kropp HA, Pinsky P, Cao Y, Chan AT, Umar A. 2019. Association of Aspirin Use With Mortality Risk Among Older Adult Participants in the Prostate, Lung, Colorectal, and Ovarian Cancer Screening Trial. JAMA Network Open 2(12): e1916729 DOI: 10.1001/jamanetworkopen

Liu Y, Lang T, Zheng Z, Cheng H, Huang X, Wang G, Yin Q, Li Y. 2019. In Vivo Environment-Adaptive Nanocomplex with Tumor Cell-Specific Cytotoxicity Enhances T Cells Infiltration and Improves Cancer Therapy. Small 15, 1902822 DOI:10.1002/smll.201902822

Lucotti S, Ridley AJ, Muschel RJ. 2019. Aspirin blocks formation of metastatic intravascular niches by inhibiting platelet- derived COX-1/thromboxane A2. J Clin Invest. 129(5):18451862 DOI:10.1172/JCI121985.

Merritt MA, Rice MS, Barnard ME. 2018. Pre-diagnosis and post-diagnosis use of common analgesics and ovarian cancer prognosis (NHS/NHSII): a prospective cohort study. Lancet Oncology DOI:10.1016/S1470-2045(18)30373-5. 
445

446

447

448

449

450

451

452

453

454

455

456

457

458

459

460

461

462

463

464

465

466

467

468

469

470

471

472

473

474

475

476

477

478

479

480

481

482

483

484

Peres LC, Camacho F, Abbott SE, Alberg AJ, Bandera EV, Barnholtz-Sloan J, Bondy M, Cote ML, Crankshaw S, Funkhouser E, Moorman PG, Peters ES, Schwartz AG, Terry P, Wang F, Schildkraut JM. 2016. Analgesic medication use and risk of epithelial ovarian cancer in african american women. Br J Cancer 114: 819-825 DOI: 10.1038/bjc.2016.39

Robles AI, Harris CC. 2010. Clinical outcomes and correlates of TP53 mutations and cancer. Cold Spring Harb Perspect Biol 2: a001016 DOI: 10.1101/cshperspect.a001016

Roberts MS, Rumble RH, Wanwimolruk S, Thomas D, Brooks PM. 1983. Pharmacokinetics of aspirin and salicylate in elderly subjects and in patients with alcoholic liver disease. Eur J Clin Pharmacol 25: 253-261 DOI: 10.1007/bf00543800

Reed SM, Quelle DE. 2014. P53 acetylation: Regulation and consequences. Cancers 7: 30-69 DOI: $10.3390 /$ cancers7010030

Raimundo L, Ramos H, Loureiro JB, Calheiros J, Saraiva L. 2020. BRCA1/P53: Two strengths in cancer chemoprevention. Biochim Biophys Acta Rev Cancer 1873(1):188339 DOI: $10.1016 /$ j.bbcan.2020.188339

Siegel RL, Miller KD, Jemal A. 2015. Cancer statistics, 2015. CA Cancer J Clin 65: 5-29 DOI:10.3322/caac. 21254

Sankaranarayanan R, Kumar DR, Altinoz MA, Bhat GJ. 2020. Mechanisms of Colorectal Cancer Prevention by Aspirin-A Literature Review and Perspective on the Role of COXDependent and -Independent Pathways. Int J Mol Sci 27;21(23):9018 DOI: 10.3390/ijms21239018

Szakacs G, Paterson JK, Ludwig JA, Booth-Genthe C, Gottesman MM. 2006. Targeting multidrug resistance in cancer. Nat Rev Drug Discov 5: 219-234 DOI: 10.1038/nrd1984

Silwal-Pandit L, Langerød A, Børresen-Dale AL. 2017. TP53 mutation in breast and ovarian cancer. Cold Spring Harb Perspect Med 7: 1-11 DOI: 10.1101/cshperspect.a026252

Skilling JS, Squatrito RC, Connor JP, Niemann T, Buller RE. 1996. p53 gene mutation analysis and antisense-mediated growth inhibition of human ovarian carcinoma cell lines. Gynecol Oncol 60: 72-80 DOI:10.1006/gyno.1996.0014

Trabert B, Ness RB, Lo-Ciganic WH, Murphy MA, Goode EL, Poole EM, Brinton LA, Webb PM, Nagle CM, Jordan SJ; Australian Ovarian Cancer Study Group, Australian Cancer Study (Ovarian Cancer), Risch HA, Rossing MA, Doherty JA, Goodman MT, Lurie G, Kjær SK, Hogdall E, Jensen A, Cramer DW, Terry KL, Vitonis A, Bandera EV, Olson S, King MG, Chandran U, Anton-Culver H, Menon U, Gayther SA. Ramus SJ, Gentry-Maharaj A, Wu AH, Pearce CL, Pike MC, Berchuck A, Schildkraut JM, Wentzensen N; Ovarian Cancer Association Consortium. 2014. Aspirin, nonaspirin nonsteroidal anti-inflammatory drug, and acetaminophen use and risk of invasive epithelial ovarian cancer: A pooled analysis in the ovarian cancer association consortium. $J$ Natl Cancer Inst 106: djt431 DOI: 10.1093/jnci/djt431

Trabert B, Poole EM, White E, Visvanathan K, Adami HO, Anderson GL, Brasky TM, Brinton LA, Fortner RT, Gaudet M, Hartge P, Hoffman-Bolton J, Jones M, Lacey JV, Larsson SC, Mackenzie GG, Schouten LJ, Sandler DP, O'Brien K, Patel AV, Peters U, 
485

486

487

488

489

490

491

492

493

494

495

496

497

498

499

500

501

502

503

504

505

506

507

508

509

510

511

512

513

Prizment A, Robien K, Setiawan VW, Swerdlow A, van den Brandt PA, Weiderpass E, Wilkens LR, Wolk A, Wentzensen N, Tworoger SS; Ovarian Cancer Cohort Consortium (OC3). 2019. Analgesic Use and Ovarian Cancer Risk: An Analysis in the Ovarian Cancer Cohort Consortium. J Natl Cancer Inst 111(2):137-145 DOI: 10.1093/jnci/djy 100

Takiuchi T, Blake EA, Matsuo K, Sood AK, Brasky TM. 2018. Aspirin use and endometrial cancer risk and survival. Gynecologic Oncology 148:222-232 DOI:10.1158/1055-9965.EPI$17-0059$

Tamura M, Sasaki Y, Koyama R, Takeda K, Idolgawa M, Tokino T. 2013. Forkhead transcription factor FOXF1 is a novel target gene of the p53 family and regulates cancer cell migration and invasiveness. Oncogene 33(40):4837-4846 DOI:10.1038/onc.2013.427

Vousden KH, Prives C. 2009. Blinded by the light: The growing complexity of p53. Cell 137: 413-431 DOI: 10.1016/j.cell.2009.04.037

Wu Y, Wang X, Xu F, Zhang L, Wang T, Fu X, Jin T, Zhang W, Ye L. 2020. The regulation of acetylation and stability of HMGA2 via the HBXIP-activated Akt-PCAF pathway in promotion of esophageal squamous cell carcinoma growth. Nucleic Acids Research. 48(9):4858-4876 DOI: 10.1093/nar/gkaa232

Wield AM, Walsh CS, Rimel BJ, Cass I, Karlan BY, Li AJ. 2018. Aspirin use correlates with survival in women with clear cell ovarian cancer. Gynecol Oncol Rep 25:78-81 DOI: 10.1016/j.gore.2018.06.004

Yamaguchi H, Woods NT, Piluso LG, Lee HH, Chen J, Bhalla KN, Monteiro A, Liu X, Hung MC, Wang HG. 2009. p53 acetylation is crucial for its transcription-independent proapoptotic functions. J Biol Chem 284:11171-83 DOI: 10.1074/jbc.M809268200

Yaginuma Y, Westphal H. 1992. Abnormal structure and expression of the p53 gene in human ovarian carcinoma cell lines. Cancer Res 52:4196-4199

Zhang D, Bai B, Xi Y, Wang T, Zhao Y. 2016. Is aspirin use associated with a decreased risk of ovarian cancer? A systematic review and meta-analysis of observational studies with doseresponse analysis. Gynecol Oncol 142: 368-377 DOI:10.1016/j.ygyno.2016.04.543 


\section{Figure legends}

515 Figure 1. Aspirin inhibits proliferation and growth and induces apoptosis in human EOC 516 cell lines in vitro.

517 (A) MTT cell viability assays were performed to determine the IC50s of aspirin in A2780, Caov-

5183 and SK-OV-3 cells over a 48-h culture period. (B) Cell proliferation was detected using EdU

519 cell proliferation assays (bar, $50 \mu \mathrm{m})$ after treatment with different concentrations of aspirin $(0$

$520 \mu \mathrm{M}, 100 \mu \mathrm{M}$, and $1000 \mu \mathrm{M}$ ) in A2780 cells. (C) Quantitative assay of proliferation rate in

521 A2780, Caov-3 and SK-OV-3 cells. (D) Colony formation assays were conducted after cells

522 were cultured with different concentrations of aspirin $(0 \mu \mathrm{M}, 25 \mu \mathrm{M}, 100 \mu \mathrm{M}, 500 \mu \mathrm{M}, 1000$

$523 \mu \mathrm{M}$, and $25 \mu \mathrm{M}$ ) for 14 days in A2780 cells. (E) Quantitative assay of colony counts in A2780,

524 Caov-3 and SK-OV-3 cells. (F) Cells were treated with different concentrations of aspirin $(0 \mu \mathrm{M}$, $525100 \mu \mathrm{M}$, and $1000 \mu \mathrm{M})$ for $48 \mathrm{~h}$ in A2780 cells, stained with the Annexin V-FITC/PI staining 526 kit, and analyzed using flow cytometry. (G)Quantitative assay of apoptosis rate in A2780, Caov5273 and SK-OV-3 cells. Data are presented as the mean \pm SD values. $* p<0.05$.

528

529

530

531

Figure 2. Aspirin enhances the CDDP sensitivity of EOC cells in vitro.

532 (A)The cell proliferation rate was determined using EdU cell proliferation assays after the incubation of A2780 cells with CDDP $(20 \mu \mathrm{M})$ alone or in combination with aspirin $(100 \mu \mathrm{M})$ (CDDP + aspirin) for $48 \mathrm{~h}$ (bar, $50 \mu \mathrm{m}$ ). (B) Quantitative assay of proliferation rate in A2780 and SK-OV-3 cells. (C) Colony formation assays were conducted to observe the growth of A2780 cells after an incubation with CDDP $(5 \mu \mathrm{M})$ alone or with aspirin $(25 \mu \mathrm{M})$ for $48 \mathrm{~h}$. (D) Quantitative assay of colony counts in A2780 and SK-OV-3 cells. (E) The percentage of apoptotic cells was determined using flow cytometry after the treatment of A2780 cells with CDDP $(20 \mu \mathrm{M})$ alone or with aspirin $(100 \mu \mathrm{M})$. (F) Quantitative assay of apoptosis rate in A2780 and SK-OV-3 cells. Data are presented as the mean \pm SD values. ${ }^{*} p<0.05$.

539

Figure 3. Aspirin enhances the CDDP sensitivity of EOC cells in vivo. surgical orthotopic implantation to observe the effects of aspirin in vivo. Aspirin was initially administered on day 9 at a dose of $20 \mathrm{mg} / \mathrm{kg}$ by gavage and then every other day thereafter, while CDDP administration was initiated at a dose of $3 \mathrm{mg} / \mathrm{kg}$ by intraperitoneal injection on day 17 and then every fourth day thereafter. Tumor growth was observed with an IVIS Lumina II beginning on day 8 and then once per week thereafter to obtain in vivo bioluminescence images. (A) The tumor signals in all mice (control group, CDDP group, and CDDP + aspirin group) at every time point are displayed. (B) The tumor growth curve for each group based on the tumor signals is shown. (C) All mice were euthanized via overdose isoflurane inhalation on day 36 and necropsied for the measurement of tumor diameters with Vernier calipers. (D) Quantitative assay of tumor volume in mice. (E) The expression levels of cleaved caspase 3, caspase 3 and Ki67 in tumor tissues harvested from mice bearing orthotopic EOC xenografts (control group, CDDP group, and CDDP + aspirin group) were assessed using IHC. (F) Quantitative assay for the IHC data of cleaved caspase 3, caspase 3 and Ki67. Data are presented as the mean \pm SD values. * 555 $\mathrm{p}<0.05$. 
557 Figure 4. Aspirin acetylates p53 in A2780 cells and subsequently activates p53-mediated 558 downregulation of target genes.

559 (A) The expression of p53 and acetylation level of p53 in tumor tissues from mice bearing 560 orthotopic EOC xenografts (control group, CDDP group, and CDDP + aspirin group) were 561 assessed using IHC. (B) Quantitative assay of positive rate in IHC. (C) Western blot analysis was 562 conducted to evaluate the level of the p53 protein and its acetylation (p53 K382-ace) after

563 treatment with different concentrations of aspirin $(0 \mu \mathrm{M}, 25 \mu \mathrm{M}, 100 \mu \mathrm{M}, 500 \mu \mathrm{M}$ and 1000 $564 \mu \mathrm{M})$. (D) Levels of the CDKN1A, BAX, FOXF1, PUMA, and RRAD mRNAs were examined 565 using qPCR after treatment with different concentrations of aspirin $(0 \mu \mathrm{M}, 100 \mu \mathrm{M}$, and 1000 $566 \mu \mathrm{M})$. Data are presented as the mean \pm SD values. $* \mathrm{p}<0.05$.

\section{Supporting figure legends}

Figure S1. Aspirin inhibits proliferation and growth and induces apoptosis in human EOC cell lines in vitro. (A) Cell proliferation was detected using EdU cell proliferation assays (bar, $50 \mu \mathrm{m})$ after treatment with different concentrations of aspirin $(0 \mu \mathrm{M}, 100 \mu \mathrm{M}$, and $1000 \mu \mathrm{M})$ in Caov-3 and SK-OV-3 cells. (B) Colony formation assays were conducted after cells were cultured with different concentrations of aspirin $(0 \mu \mathrm{M}, 25 \mu \mathrm{M}, 100 \mu \mathrm{M}, 500 \mu \mathrm{M}, 1000 \mu \mathrm{M}$, and $25 \mu \mathrm{M}$ ) for 14 days in Caov-3 and SK-OV-3 cells. (B) Cells were treated with different concentrations of aspirin $(0 \mu \mathrm{M}, 100 \mu \mathrm{M}$, and $1000 \mu \mathrm{M})$ for $48 \mathrm{~h}$ in Caov-3 and SK-OV-3 cells, stained with the Annexin V-FITC/PI staining kit, and analyzed using flow cytometry.

577

Figure S2. In vitro evidence that aspirin inhibits the migration of human EOC cell lines. (A) Wound healing assays were conducted to observe the migration of A2780, Caov-3 and SKOV-3 cells after treatment with different concentrations of aspirin $(0 \mu \mathrm{M}, 100 \mu \mathrm{M}$, and $1000 \mu \mathrm{M}$; bar, $100 \mu \mathrm{m}$ ) for $24 \mathrm{~h}$. (B) Quantitative assay of migration rate in A2780, Caov-3 and SK-OV-3 cells. (C) The cell migration rate was determined by performing transwell migration assays after the incubation of A2780, Caov-3 and SK-OV-3 cells with different concentrations of aspirin (0 $\mu \mathrm{M}, 100 \mu \mathrm{M}$, and $1000 \mu \mathrm{M}$; bar, $100 \mu \mathrm{m}$ ) for $48 \mathrm{~h}$. (D) Quantitative assay of migrating cell counts in A2780, Caov-3 and SK-OV-3 cells. Data are presented as the mean \pm SD values. * $\mathrm{p}<0.05$.

Figure S3. Aspirin enhances the CDDP sensitivity of EOC cells in vitro. (A)The cell proliferation rate was determined using EdU cell proliferation assays after the incubation of SKOV-3 cells with CDDP $(20 \mu \mathrm{M})$ alone or in combination with aspirin $(100 \mu \mathrm{M})(\mathrm{CDDP}+$ aspirin) for $48 \mathrm{~h}$ (bar, $50 \mu \mathrm{m}$ ). (B) Colony formation assays were conducted to observe the growth of SK-OV-3 cells after an incubation with CDDP $(5 \mu \mathrm{M})$ alone or with aspirin $(25 \mu \mathrm{M})$ for $48 \mathrm{~h}$. (C) The percentage of apoptotic cells was determined using flow cytometry after the treatment of SK-OV-3 cells with CDDP $(20 \mu \mathrm{M})$ alone or with aspirin $(100 \mu \mathrm{M})$. 


\section{Figure 1}

Aspirin inhibits proliferation and growth and induces apoptosis in human EOC cell lines in vitro.

(A) MTT cell viability assays were performed to determine the IC50s of aspirin in A2780, Caov-3 and SK-OV-3 cells over a 48-h culture period. (B) Cell proliferation was detected using EdU cell proliferation assays (bar, $50 \mu \mathrm{m}$ ) after treatment with different concentrations of aspirin $(0 \mu \mathrm{M}, 100 \mu \mathrm{M}$, and $1000 \mu \mathrm{M})$ in A2780 cells. (C) Quantitative assay of proliferation rate in A2780, Caov-3 and SK-OV-3 cells. (D) Colony formation assays were conducted after cells were cultured with different concentrations of aspirin $(0 \mu \mathrm{M}, 25 \mu \mathrm{M}, 100 \mu \mathrm{M}, 500 \mu \mathrm{M}$, $1000 \mu \mathrm{M}$, and $25 \mu \mathrm{M}$ ) for 14 days in A2780 cells. (E) Quantitative assay of colony counts in A2780, Caov-3 and SK-OV-3 cells. (F) Cells were treated with different concentrations of aspirin $(0 \mu \mathrm{M}, 100 \mu \mathrm{M}$, and $1000 \mu \mathrm{M})$ for $48 \mathrm{~h}$ in A2780 cells, stained with the Annexin VFITC/PI staining kit, and analyzed using flow cytometry. (G)Quantitative assay of apoptosis rate in A2780, Caov-3 and SK-OV-3 cells. Data are presented as the mean \pm SD values. * $p<0.05$. 
(A)

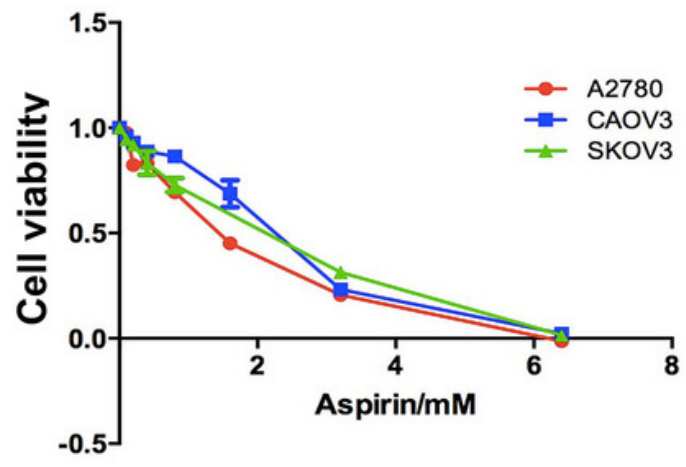

(B)

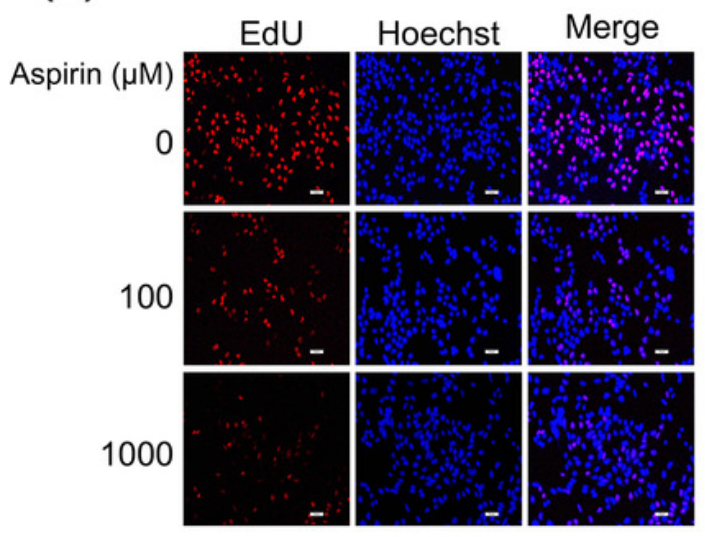

A2780

(D)

Aspirin $\quad 0 \mu \mathrm{M} \quad 25 \mu \mathrm{M} \quad 100 \mu \mathrm{M}$

Aspirin $\quad 500 \mu \mathrm{M} \quad 1000 \mu \mathrm{M}$ Blank

A2780

(F)

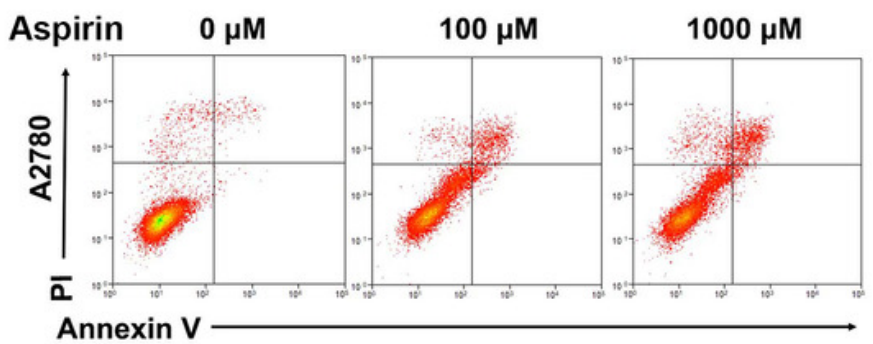

(C)

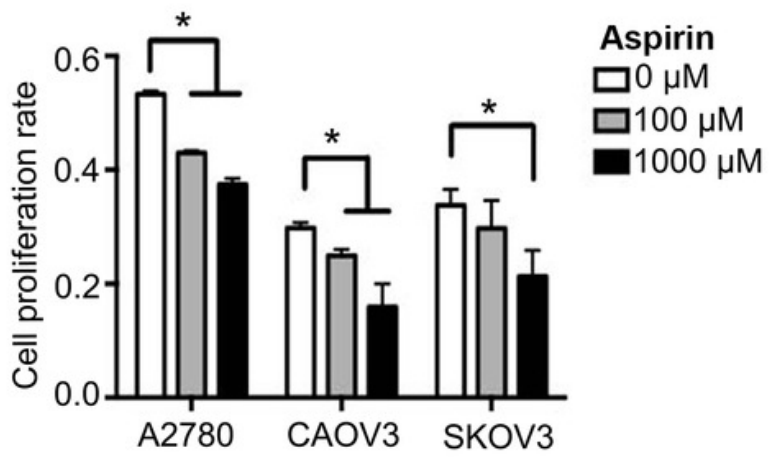

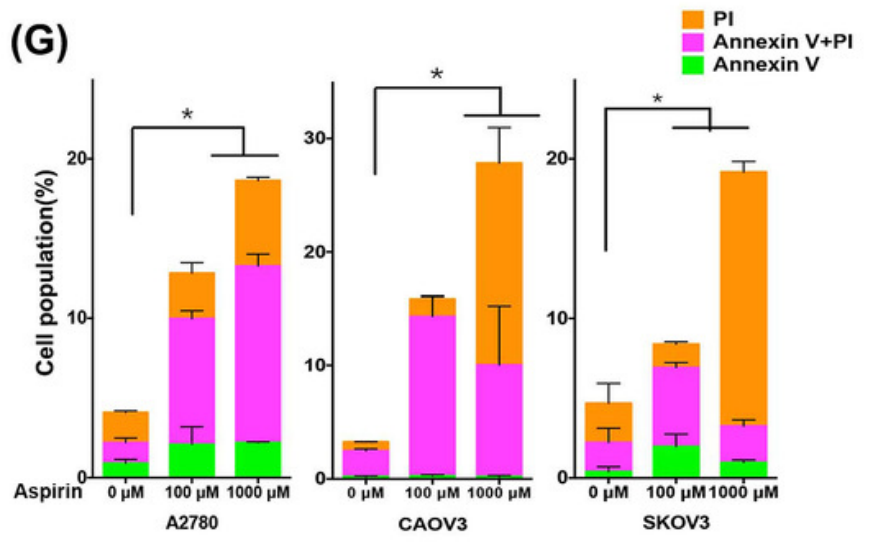




\section{Figure 2}

Aspirin enhances the CDDP sensitivity of EOC cells in vitro.

(A)The cell proliferation rate was determined using EdU cell proliferation assays after the incubation of A2780 cells with CDDP $(20 \mu \mathrm{M})$ alone or in combination with aspirin $(100 \mu \mathrm{M})$ (CDDP + aspirin) for $48 \mathrm{~h}$ (bar, $50 \mu \mathrm{m}$ ). (B) Quantitative assay of proliferation rate in A2780 and SK-OV-3 cells. (C) Colony formation assays were conducted to observe the growth of A2780 cells after an incubation with CDDP ( $5 \mu \mathrm{M})$ alone or with aspirin $(25 \mu \mathrm{M})$ for $48 \mathrm{~h}$. (D) Quantitative assay of colony counts in A2780 and SK-OV-3 cells. (E) The percentage of apoptotic cells was determined using flow cytometry after the treatment of A2780 cells with CDDP $(20 \mu \mathrm{M})$ alone or with aspirin $(100 \mu \mathrm{M})$. (F) Quantitative assay of apoptosis rate in A2780 and SK-OV-3 cells. Data are presented as the mean \pm SD values. $* p<0.05$. 
(A)

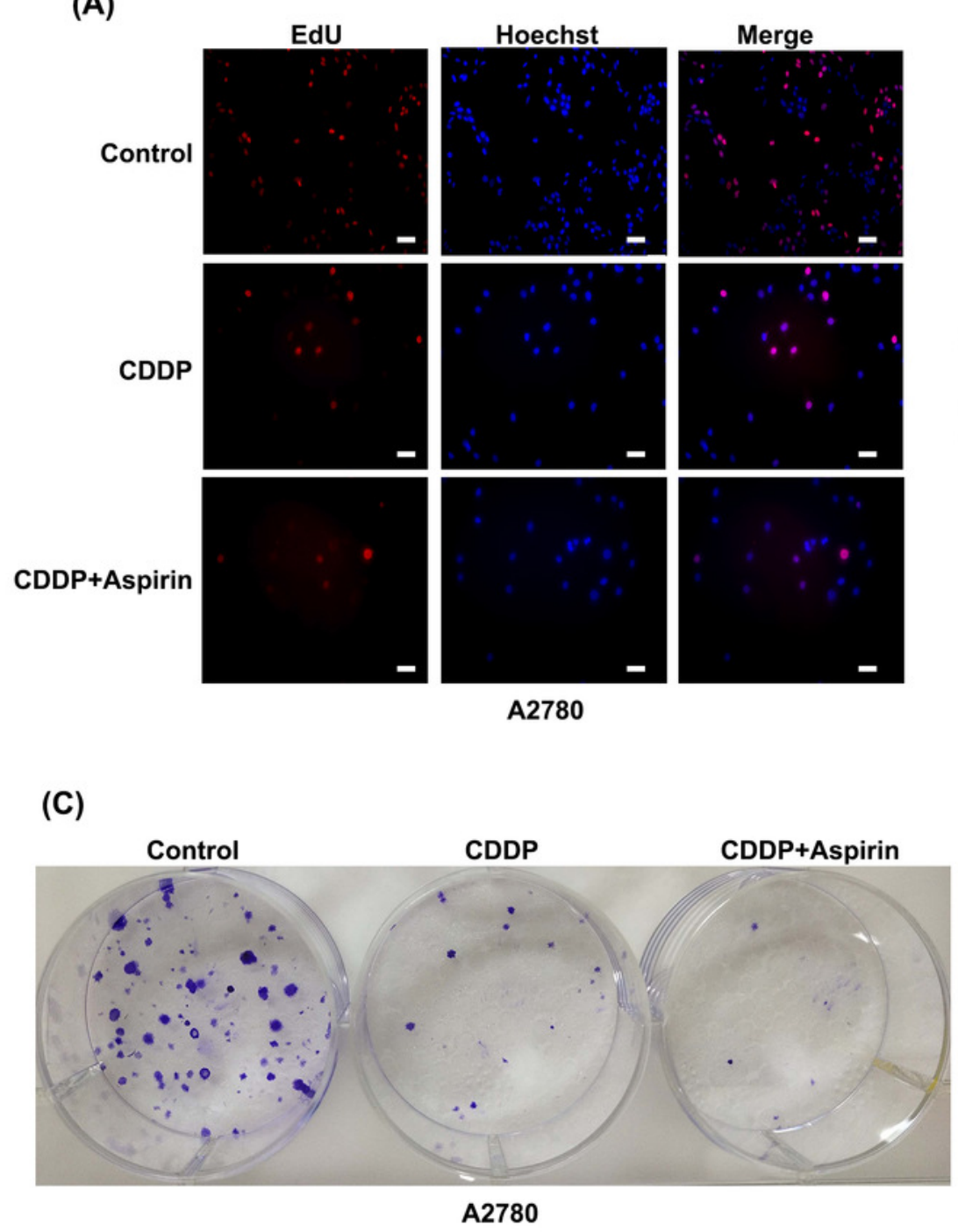

(E)

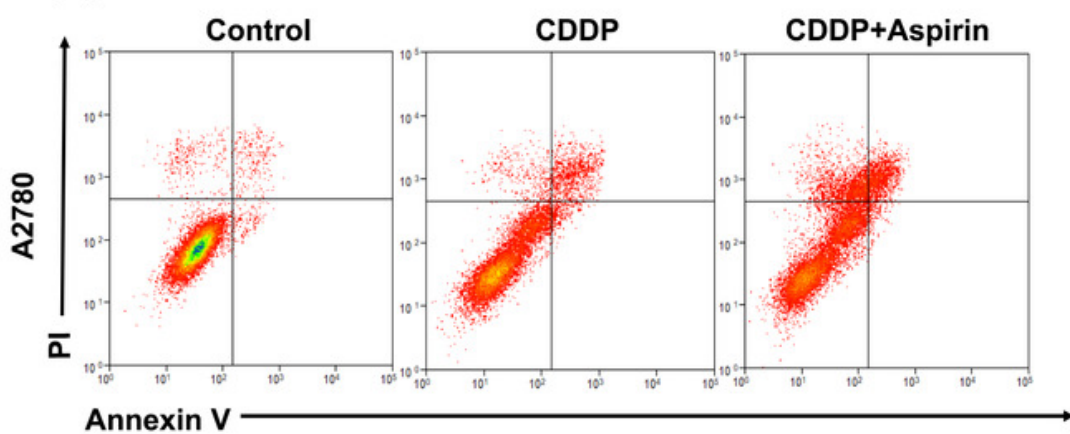

(B)
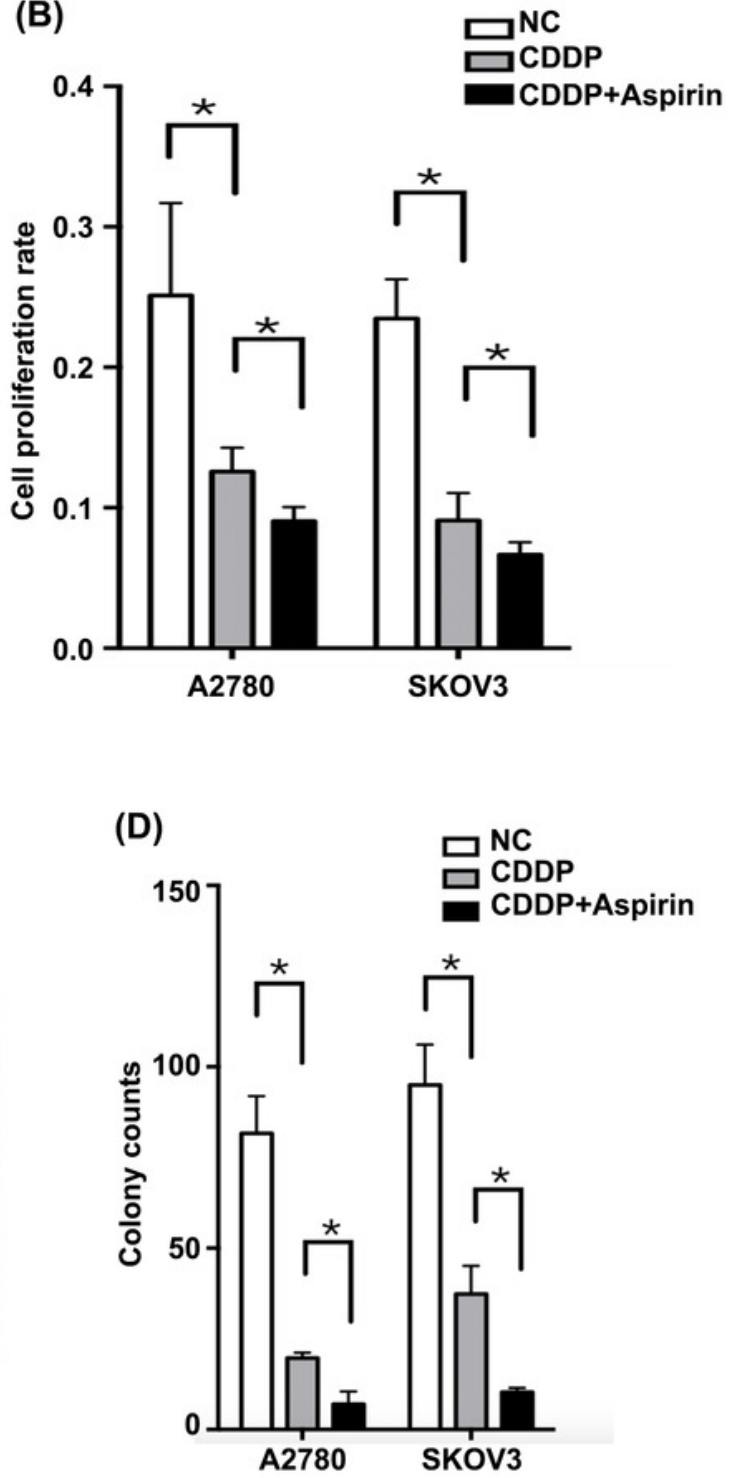

(F)

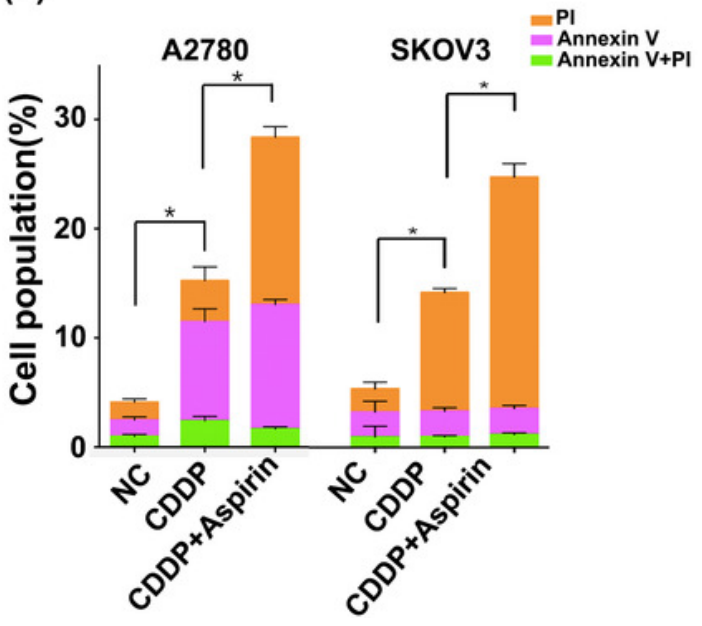




\section{Figure 3}

Aspirin enhances the CDDP sensitivity of EOC cells in vivo.

Orthotopic xenograft mouse models of EOC were established with A2780-Luciferase cells using surgical orthotopic implantation to observe the effects of aspirin in vivo. Aspirin was initially administered on day 9 at a dose of $20 \mathrm{mg} / \mathrm{kg}$ by gavage and then every other day thereafter, while CDDP administration was initiated at a dose of $3 \mathrm{mg} / \mathrm{kg}$ by intraperitoneal injection on day 17 and then every fourth day thereafter. Tumor growth was observed with an IVIS Lumina II beginning on day 8 and then once per week thereafter to obtain in vivo bioluminescence images. (A) The tumor signals in all mice (control group, CDDP group, and CDDP + aspirin group) at every time point are displayed. (B) The tumor growth curve for each group based on the tumor signals is shown. (C) All mice were euthanized via overdose isoflurane inhalation on day 36 and necropsied for the measurement of tumor diameters with Vernier calipers. (D) Quantitative assay of tumor volume in mice. (E) The expression levels of cleaved caspase 3, caspase 3 and Ki67 in tumor tissues harvested from mice bearing orthotopic EOC xenografts (control group, CDDP group, and CDDP + aspirin group) were assessed using IHC. (F) Quantitative assay for the IHC data of cleaved caspase 3, caspase 3 and Ki67. Data are presented as the mean \pm SD values. $* p<0.05$. 

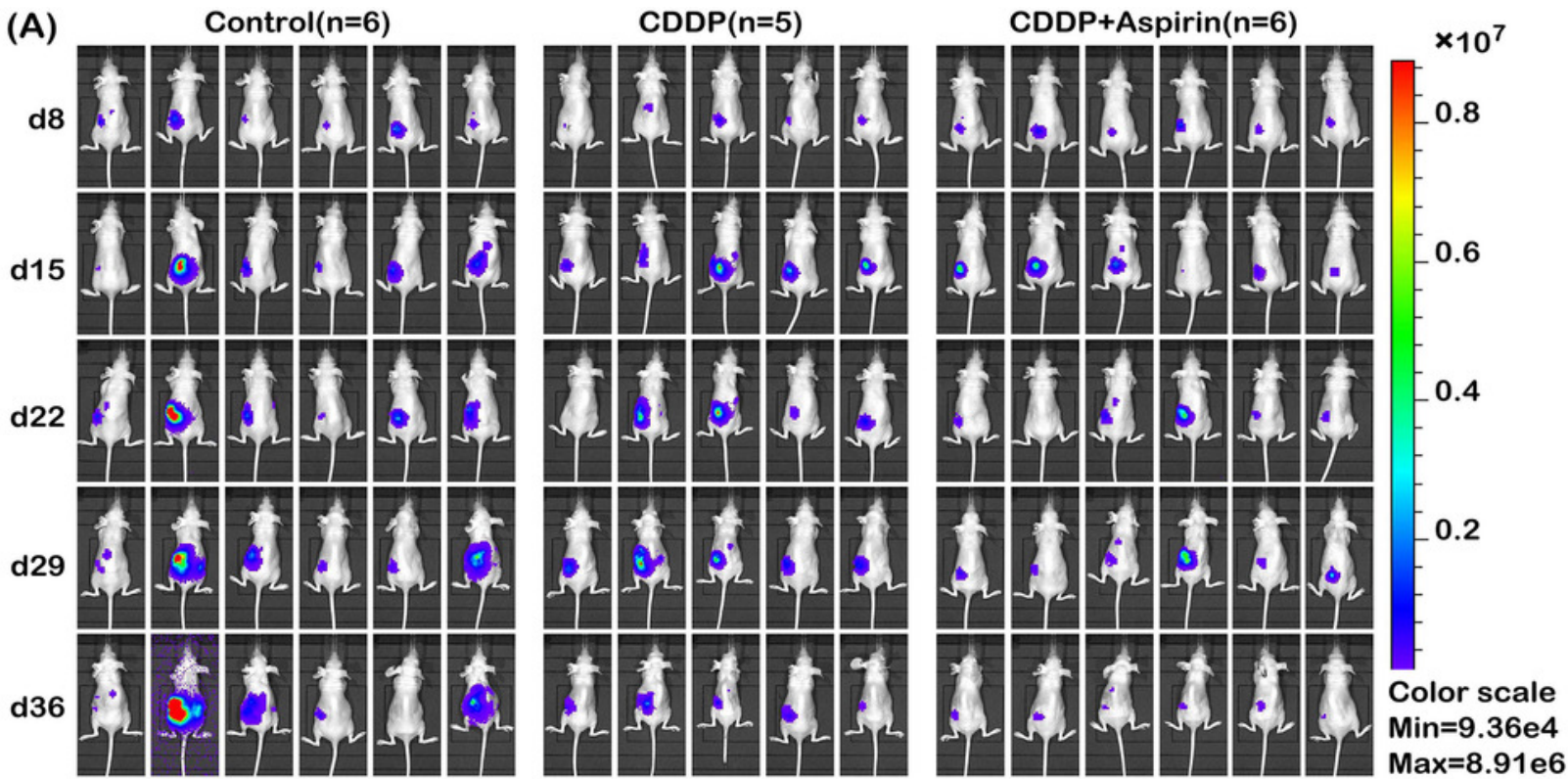

(B)
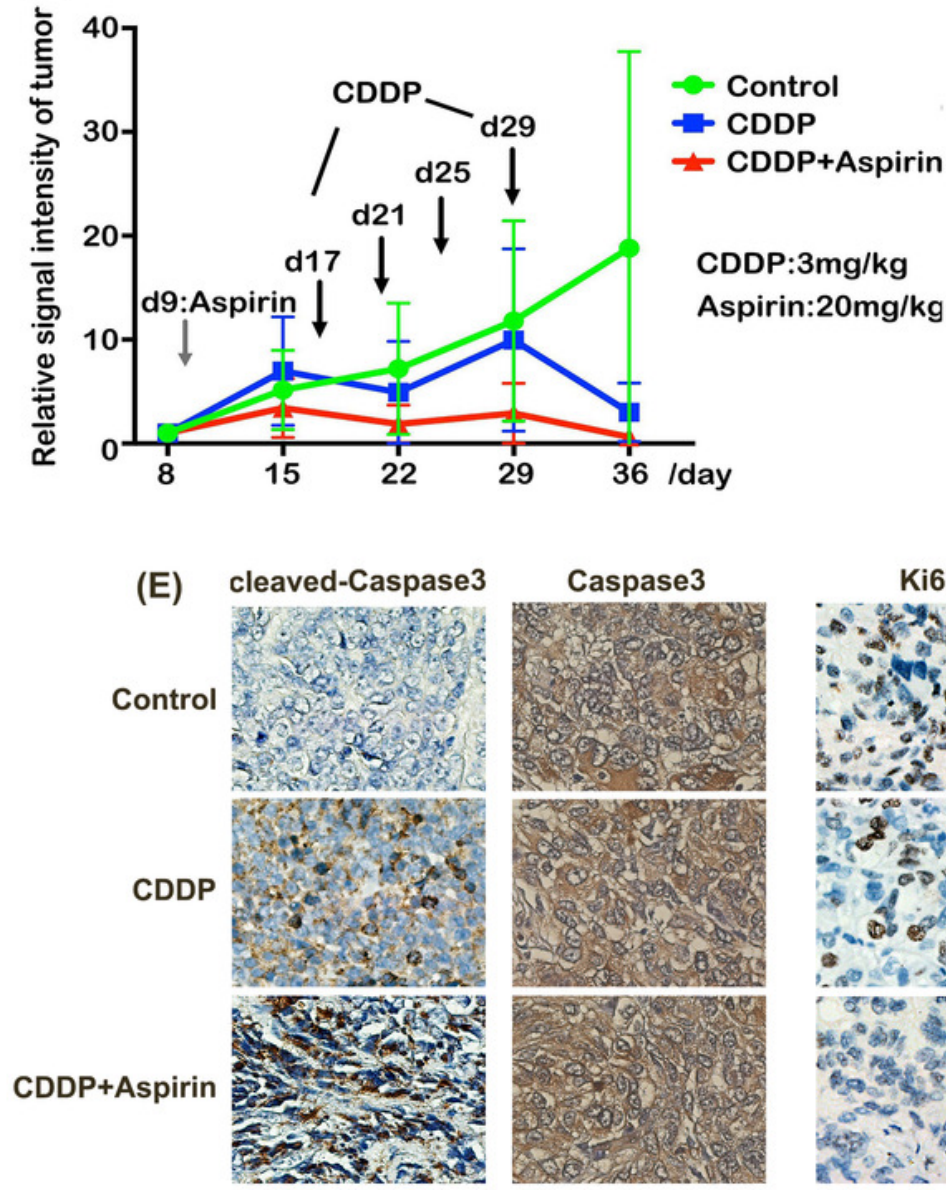

(C)

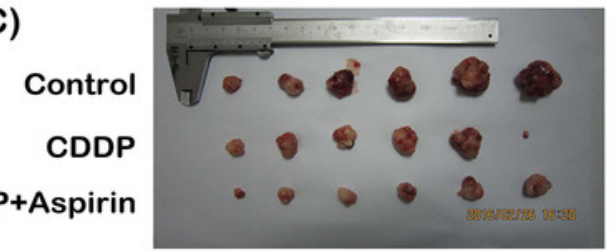

(D)

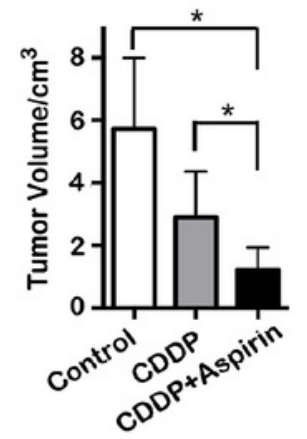

(F) $\begin{array}{ll}\text { 吕 control } \\ \text { CDDP } \\ \text { CDDP+Aspirin }\end{array}$

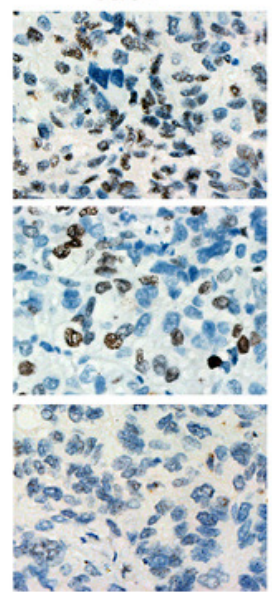

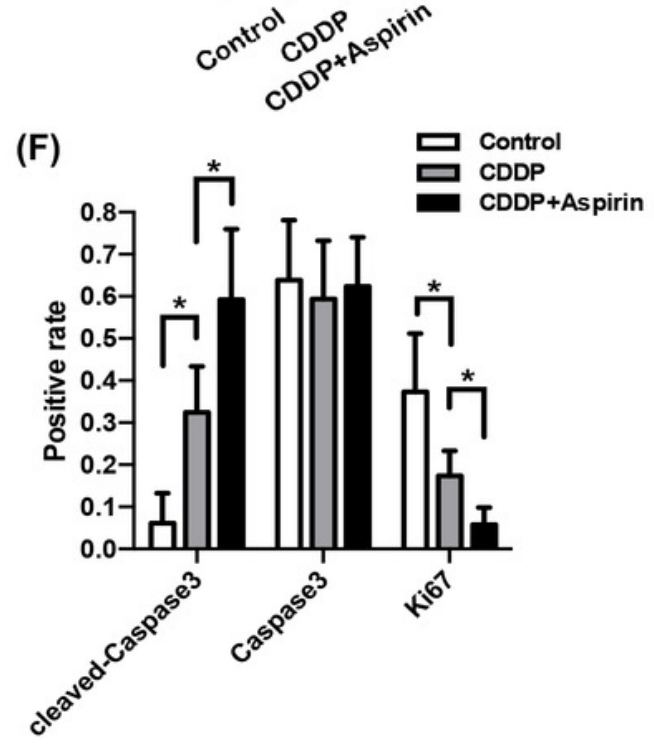




\section{Figure 4}

Aspirin acetylates p53 in A2780 cells and subsequently activates p53-mediated downregulation of target genes.

(A) The expression of p53 and acetylation level of p53 in tumor tissues from mice bearing orthotopic EOC xenografts (control group, CDDP group, and CDDP + aspirin group) were assessed using IHC. (B) Quantitative assay of positive rate in IHC. (C) Western blot analysis was conducted to evaluate the level of the p53 protein and its acetylation (p53 K382-ace) after treatment with different concentrations of aspirin $(0 \mu \mathrm{M}, 25 \mu \mathrm{M}, 100 \mu \mathrm{M}, 500 \mu \mathrm{M}$ and $1000 \mu \mathrm{M})$. (D) Levels of the p21, bax, foxf1, puma, and rad mRNAs were examined using qPCR after treatment with different concentrations of aspirin $(0 \mu \mathrm{M}, 100 \mu \mathrm{M}$, and $1000 \mu \mathrm{M})$. Data are presented as the mean \pm SD values. $* p<0.05$. 


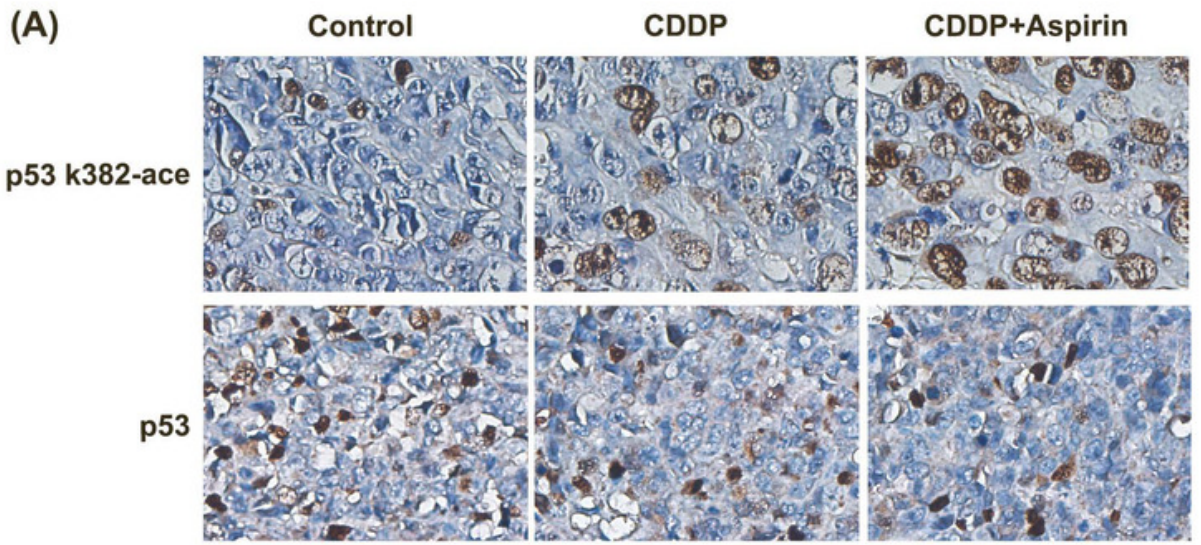

(C)

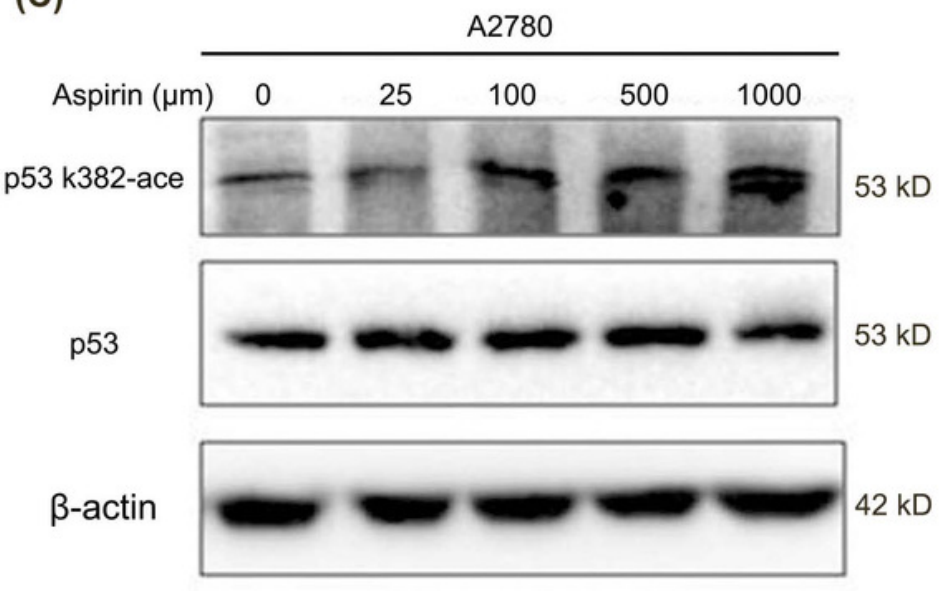

(D)

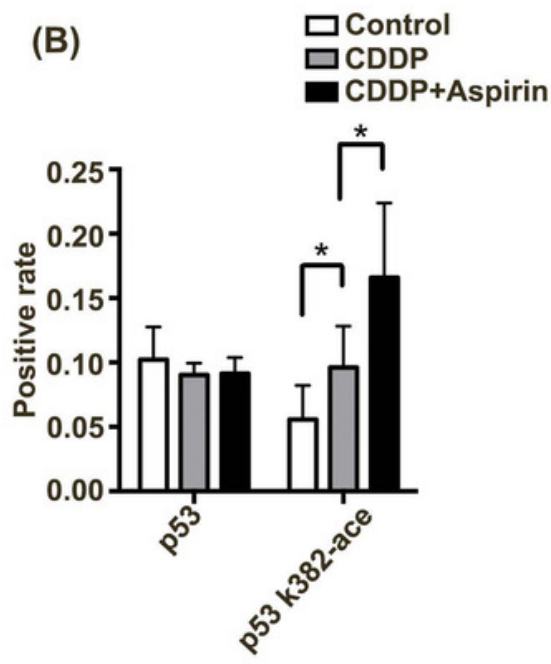

\section{A2780}

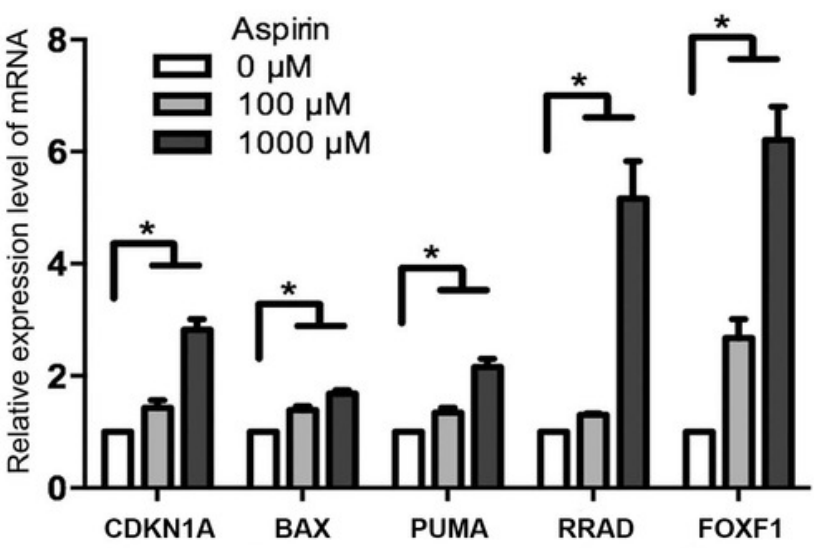

